\title{
Qualitative and Quantitative Determination of Organic Acids in Crude Herbal Drugs and Medicinal Herbal Preparations for Quality Control in Russian Federation by Modern Physicochemical Methods
}

\author{
Ekaterina Vyacheslavovna Sergunova ${ }^{1, *}$, Alla Anatolyevna Sorokina', Dmitry Olegovich Bokov ${ }^{1,2,3}$, Anna \\ Igorevna Marakhova ${ }^{4}$
}

\section{Ekaterina Vyacheslavovna \\ Sergunova ${ }^{1, *}$, Alla \\ Anatolyevna Sorokina', \\ Dmitry Olegovich Bokov ${ }^{1,2,3}$, \\ Anna Igorevna Marakhova ${ }^{4}$}

'Department of Pharmaceutical and Natural Sciences, Sechenov First Moscow

State Medical University, 8 Trubetskaya St., bldg. 2, 119991, RUSSIA.

${ }^{2}$ Department of Analytical, Physical and

Colloid Chemistry, Sechenov First Moscow

State Medical University, 8 Trubetskaya St.,

bldg. 2, 119991, RUSSIA.

'Laboratory of Food Chemistry,

Federal Research Center for Nutrition,

Biotechnology and Food Safety, 2/14,

Ustyinsky pr., Moscow, 109240, RUSSIA.

${ }^{4}$ Institute of Biochemical Technology and

Nanotechnology, Peoples' Friendship

University of Russia (RUDN University),

Miklukho-Maklaya St., 6, Moscow, 117198,

RUSSIA.

\section{Correspondence}

Ekaterina Vyacheslavovna Sergunova

Department of Pharmaceutical and

Natural Sciences, Sechenov First Moscow

State Medical University, 8 Trubetskaya

St., bldg. 2, 119991, RUSSIA

E-mail: nakası@mail.ru

History

- Submission Date: 07-06-2019;

- Review completed: 19-06-2019;

- Accepted Date: 18-07-2019

DOI : 10.5530/pj.2019.11.176

Article Available online

http://www.phcogj.com/v11/i5

Copyright

(C) 2019 Phcogj.Com. This is an openaccess article distributed under the terms of the Creative Commons Attribution 4.0 International license.

\begin{abstract}
Background: Organic acids (malic, citric, tartaric, oxalic, acetic, formic, isovaleric, ascorbic acids) make up a large group of biologically active substances and play an important role in plant and human metabolism. They are found in large quantities in the fruits of Rosaceae family medicinal plants that included in State Pharmacopoeia of the Russian Federation. Standardization of crude herbal drugs containing organic acids by modern physicochemical methods is a high-priority task.
\end{abstract}

Materials and methods: The determination of total organic acids amount was carried out in aqueous extracts from different fruits of Rosaceae family plants by galvanostatic coulometry and potentiometry methods. Galvanostatic coulometry was performed with the help of the "Expert-006" coulometer with a current of $5 \mathrm{~mA}$ (integrated $\mathrm{pH}$ meter). lodine as an electrogenerated titrant was used for ascorbic acid determination; electro generation of hydroxide ions was carried out for determination of total organic acids amount. A potentiometer "Aquilon pH-410" with attached glass and silver chloride electrodes was used for potentiometric determination of total organic acids amount. Individual organic acids have been determined by reverse-phase high-performance liquid chromatography with ultra-violet detection (RP-HPLCUV) method. The following conditions were established: Gilson HPLC system, Alltech OA1000 Organic Acids $(6.5 \times 300 \mathrm{~mm}, 9 \mu \mathrm{m})$ chromatography column, a gradient elution mode, component $\mathrm{A}$ of the mobile phase is $98 \%\left(0.1 \%\right.$ phosphoric acid, $10 \mathrm{mM} \mathrm{KH}_{2} \mathrm{PO}_{4}$, solution in water) with $2 \%$ acetonitrile, component $B$ is acetonitrile, the eluent feed rate is $1 \mathrm{ml} / \mathrm{min}$. Results: Modern physicochemical methods for the analysis of biologically active substances, organic acids, for quality control of crude herbal drugs and medicinal herbal preparations, are developed and discussed. The optimal conditions for the qualitative and quantitative organic acid analysis are selected and described taking into account modern pharmacopoeial requirements.

Conclusion: Galvanostatic coulometry and potentiometry methods, as well as RP-HPLC-UV, can be successfully used in the quality control of crude herbal drugs and medicinal herbal preparations, specifically fruits of Rosaceae family plants. Development and validation of analytical methods for monitoring the content of this BAS group is an important research area in the pharmacopoeial standardization of crude herbal drugs.

Key words: Crude herbal drugs, Organic acids, Titrimetric Methods, Coulometry, Potentiometry, Redox titration, High performance liquid chromatography.

\section{INTRODUCTION}

The current level of natural biologically active substances (BAS) analysis, as well as issues related to the development and improvement of standardization procedures, requires the use of exact physicochemical methods in quality control of crude herbal drugs. The main problem in the crude herbal drugs (CHD) standardization associated with the multicomponent BAS composition with different physicochemical nature and the mutual interaction of some BAS groups with others. The range expansion of the medicinal herbal preparations nomenclature (both domestic and foreign production) is associated with the development of evidence-based pharmacology, the discovery of new BAS properties. Drugs of natural origin must meet the quality criteria, their determination should be carried out by objective and modern physicochemical methods. ${ }^{1-3}$

Organic acids, (OA: malic, citric, tartaric, oxalic, acetic, formic, isovaleric, ascorbic acids) make up a large group of BAS and play an important role in plant metabolism. They are intermediate compounds during the oxidation of carbohydrates, fats, amino 
acids, and proteins. OA have a wide range of biological effects on the human body: in addition to vitamin properties, they have a choleretic effect that normalizes the activity of the digestive system. OA regulate the secretion of bile and pancreatic juice, improve appetite; have bactericidal properties and reduce the putrefactive processes in the body. Ascorbic acid, increasing the redox processes in tissues, plays an important role in a skin barrier function, promotes regeneration with various injuries by stimulating assimilation and dissimilation processes; reduces melanogenesis in the epidermis, has a specific effect on the capillary walls, stimulating the synthesis of procollagen and turning it into collagen; promotes glucose utilization, reduces tissue permeability, inhibits hydrolytic reactions, which plays an important role in the regeneration of burns. ${ }^{1,2}$

$\mathrm{OA}$ are found in large quantities in the fruits of Rosaceae family medicinal plants (redhaw hawthorn (Crataegus sanguinea Pall.), ${ }^{4,5}$ European mountain ash (Sorbus aucuparia L.) ${ }^{6-8}$ common raspberry (Rubus idaeus L.), ${ }^{9,10}$ Cinnamon rosehip (Rosa majalis Herrm.)), ${ }^{11}$ and Caprifoliaceae family medicinal plants (European dogwood (Viburnum opulus L.))..$^{12,13}$ The aim of the research is to study the composition and content of organic acids in the Russian medical plants by various methods and to determine the most suitable option for pharmacopoeial analysis.

\section{MATERIALS AND METHODS}

The determination of organic acids was performed in aqueous extracts obtained from different fruits of Rosaceae family plants by galvanostatic coulometry and potentiometry methods. Per the requirements of the State Pharmacopoeia of the Russian Federation XI Edition, the determination of the total OA amount in rosehips, used for medicinal herbal preparations (rosehip syrup, "Holosas", "Karotolin"), was determined by acid-base titration method. Rosehips aqueous extract is titrated by $0.1 \mathrm{~mol} / \mathrm{l}$ solution of sodium hydroxide in the presence of indicators (methylene blue and phenolphthalein) until a violet-pink color appears in the foam. At the same time, according to this method, it is recommended to conduct a substantial and approximate dilution of $10 \mathrm{ml}$ of extracts with freshly boiled water in a volume of 200-300 $\mathrm{ml}$. The acid-base titration technique with an indicator has several drawbacks: it requires prior standardization of the titrant, implies the use of indicators, the color transition of indicators can be established with a certain accuracy only after significant dilution of the extract. OA titration process occurs before the appearance of a lilac-pink color in the foam, which also does not give an accurate result of the titration endpoint; also there is the inability to analyze colored solutions that do not form a foam when shaken. These facts consequently lead to a failure to identify the titration endpoint.

The determination of ascorbic acid in crude herbal drugs is recommended to be carried out by titration with a solution of 2,6-dichloroindophenol sodium salt according to the method of the State Pharmacopoeia of Russian Federation XI edition (SPRF XI) of the monograph "Rosae fructus" (rosehips). The disadvantages are also the inaccuracy of the results, the difficulty in determining the titration endpoint due to the intrinsic color of the fruit extracts, the possible influence of other BAS that have redox properties. ${ }^{2,14,15}$

Taking into account the above-mentioned disadvantages of titration methods with indicators, it has recently become increasingly common to determine the OA content in crude herbal drugs using electrochemical methods - potentiometric and coulometric titration.

Galvanostatic coulometry was performed with the help of the "Expert-006" coulometer (Econix-Expert, Russia) with a current of 5 $\mathrm{mA}$ (integrated $\mathrm{pH}$ meter) ${ }^{16}$ Iodine as an electrogenerated titrant was used for ascorbic acid determination. Electro-generated iodine was obtained from a $0.1 \mathrm{M}$ KI solution in hydrochloric acid and potassium chloride ( $\mathrm{pH}$ 1.2). Testing the effectiveness of coulometric titration is carried out according to the standard titer "Sodium sulfate 5-hydrate $\left(\mathrm{Na}_{2} \mathrm{~S}_{2} \mathrm{O}_{3} \cdot 5 \mathrm{H}_{2} \mathrm{O}\right)=0.1 \mathrm{~mol} / \mathrm{dm}^{3}(0.1 \mathrm{~N})$.

The amount of electricity spent on titration experimentally on the coulometer "Expert-006", is calculated by the formula:

$$
\mathrm{Q}_{\exp }=\frac{m \cdot 10^{-6} \cdot 1 \cdot 96485,3}{248,2}(\mathrm{C}),
$$

where $\mathrm{m}$ - the mass of sodium thiosulfate in the sample, found coulometrically, $\mu \mathrm{g}$ (there should be $124.1 \mu \mathrm{g}$ ). Ascorbic acid interacts with an electrogenerated iodine quickly and in stoichiometric amounts in a $1: 1$ ratio.

Electrogeneration of hydroxide ions was carried out for the determination of total organic acids amount.

A potentiometer "Aquilon $\mathrm{pH}-410$ " (Aquilon, Russia) with attached glass and silver chloride electrodes was used for potentiometric determination of total organic acids amount.

Individual organic acids have been determined by RP-HPLC-UV method. Gilson HPLC system (Villiers Le Bel, France) with the subsequent computer processing of the research results using the "Multichrome" program for "Windows". Chromatography column "Alltech OA-1000 Organic Acids" $(6.5 \times 300 \mathrm{~mm}, 9 \mu \mathrm{m})$ was used as a stationary phase. The separation of $\mathrm{OA}$ is carried out in a gradient elution mode, component $\mathrm{A}$ of the mobile phase is $98 \%(0.1 \%$ phosphoric acid, $10 \mathrm{mM} \mathrm{KH}_{2} \mathrm{PO}_{4}$, solution in water) $+2 \%$ acetonitrile, component $\mathrm{B}$ is acetonitrile, at room temperature, the eluent feed rate is $1 \mathrm{ml} / \mathrm{min}$.

\section{RESULTS AND DISCUSSION}

The method of galvanostatic coulometry, in particular, coulometric titration, is characterized by high accuracy, speed, simplicity of the experiment, does not require preliminary standardization of the titrant, use of standard samples, construction of calibration graphs and is relevant for the analysis of BAS in CHD. Time and amperage are the main controlled parameters in coulometric titration. ${ }^{17,18}$ Modern devices allow measuring automatically these parameters with very high accuracy. A distinctive feature of galvanostatic coulometry is the possibility of obtaining a large number of electrogenerated titrants (Figure 1) in both aqueous and non-aqueous media that can possess various types of chemical reactions (redox, precipitating, acid-base types) with the test substance, which significantly expands the range of defined compounds. The unification of analytical methods is equally important. Since it is the basis for improving and simplifying analytical control methods. A unified approach to the analysis of herbal medicines and herbal medicines is being formed, the analysis time and the reagents quantity are reduced.

As a rule, the model sample is the aqueous extract from the rosehips. Coulometric curves of ascorbic acid titration and aqueous extracts from rosehips have a similar character (Figure 2) and it can be assumed that ascorbic acid is titrated in aqueous extract under these conditions.

It is very promising to determine the total OA content in the fruits of mountain ash, wild rosehips (pharmacopoeia species) and European dogwood by electrogenerated hydroxide ions. ${ }^{19,20}$ It is established that malic acid interacts with electrogenerated hydroxide ions quickly and quantitatively in a 1:2 ratio. The similarity of the curves of titration of malic acid and aqueous extract from rosehips suggests that in the aqueous extract, the amount of $\mathrm{OA}$ is titrated under the conditions found (Figure 3). 


\begin{tabular}{|c|c|c|}
\hline \multicolumn{3}{|c|}{ Electrogenerated titrants } \\
\hline \multicolumn{3}{|c|}{$\downarrow$} \\
\hline \multicolumn{3}{|c|}{ Aqueous media } \\
\hline & $\downarrow$ & \\
\hline Iodine & Bromine & Hydroxide ions \\
\hline & $\downarrow$ & y \\
\hline $\begin{array}{l}\text { determination of } \\
\text { ascorbic acid in CHD } \\
\text { (acidic medium) }\end{array}$ & $\begin{array}{l}\text { determination of } \\
\text { arbutin in CHD } \\
\text { (acidic medium) }\end{array}$ & $\begin{array}{c}\text { determination of } \\
\text { organic } \\
\text { acids in herbal } \\
\text { drugs }\end{array}$ \\
\hline
\end{tabular}

Figure 1: Diagram of electrogenerated titrants use in pharmaceutical analysis.
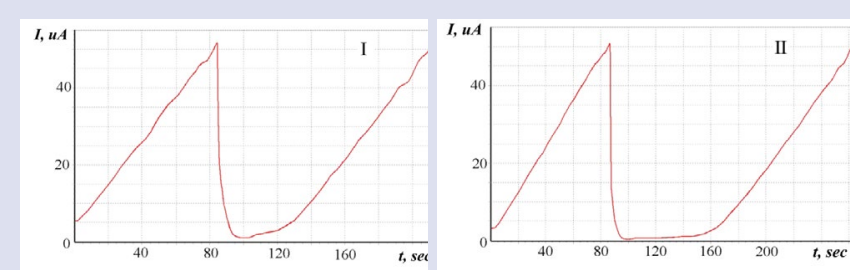

Figure 2: Coulometric curves of ascorbic acid titration (I) and aqueous extract from the rosehips (II).
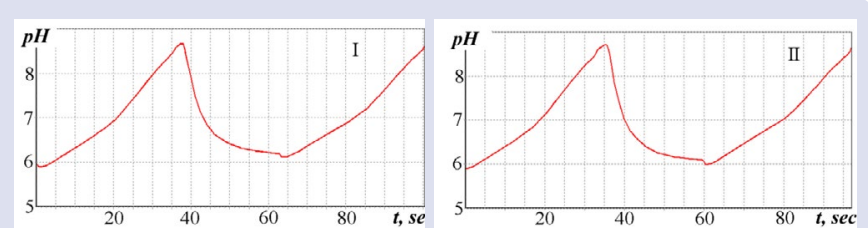

Figure 3: Coulometric curves of malic acid titration (I) and rosehips aqueous extract (II).

For research, the instruments of the Expert-006 coulometer with a current of $5 \mathrm{~mA}$ were used; $\mathrm{pH}$ meter is built into the coulometer. Electrogeneration of hydroxide ions was carried out from a saturated $\mathrm{K}_{2} \mathrm{SO}_{4}$ aqueous solution, the titration endpoint was determined $\mathrm{pH}$ metrically using an ESC-10614 laboratory combined semi-micro-pH electrode. The composition of the background electrolyte: $\mathrm{K}_{2} \mathrm{SO}_{4}$ (sat.): $\mathrm{H}_{2} \mathrm{O}(1: 7)$, there is a $100 \%$ current output. The efficiency of coulometric titration has been proposed to be checked using the standard titer "Hydrochloric acid C $(\mathrm{HCl})=0.1 \mathrm{~N}$ ".

Potentiometry is an electrochemical method of analysis based on determining the amount of a substance in an analyzed sample from the magnitude of the electrode potential. Modern potentiometers are distinguished by their compactness, ease of calibration, ease of use due to a capacious battery, a complete set of electrodes, a stand for them, and a thermal compensator. The advantage of potentiometric titration is the ease of analysis, high accuracy, and sensitivity, the ability to more accurately indicate titration endpoint and titration in turbid and colored media, work with extracts without dilution, analysis of aqueous and non-aqueous extracts, the possibility of automating the titration process. Among the disadvantages of the method, it is possible to note the relative duration of the titration associated with the need for time to establish the equilibrium. ${ }^{21,22}$

An acid-base reaction is used as a titration reaction in acid-base potentiometric titration, an i.e. reaction involving protons. Therefore, the titration curve in acid-base potentiometric titration will be the dependence of the $\mathrm{pH}$ of the test solution on the volume of the titrant added. When titrating the total OA amount with indicators in hips, viburnum, mountain ash, black currant, the content of phenolic compounds titrated with sodium hydroxide is neglected. This may affect the accuracy of titrimetric analysis using indicators due to an error in the results. Similar problems can be avoided by potentiometric determination of equivalent volume. ${ }^{15,23,24}$

In our work, a potentiometer "Aquilon $\mathrm{pH}-410$ " with attached glass and silver chloride electrodes was used. The freshly prepared extract is titrated with $0.1 \mathrm{M}$ sodium hydroxide solution from a microburette with constant stirring using a magnetic stirrer. The potentiometer readings are fixed after the establishment of equilibrium, and according to the obtained results, titration curves are plotted in the coordinates of $\mathrm{pH}(\mathrm{V})$ to determine the equivalence point (for example, extracting rosehips) (Figure 4). The titration curve has a typical form for the titration of weak acids with a strong base.

It is necessary to carry out validation to prove the possibility of including methods of potentiometric and coulometric titration of ascorbic acid and the total OA amount in terms of malic acid in the regulatory documentation (RD) of the Russian Federation. The validation procedure includes the determination of specificity, detection limit, quantitation limit, analytical area (range), linearity, trueness, precision, robustness.

At present, physicochemical methods in the analysis of crude herbal drugs and medicinal herbal preparations are prioritized. These methods provide great opportunities for the quantitative determination of different groups of biologically active substances (organic acids, flavonoids, tannins, the elemental composition of CHD).

Discussing here the modern physicochemical analysis methods, it should not go unnoticed an instrumental chromatographic method of high-performance liquid chromatography (HPLC). HPLC is a column chromatography method in which a liquid phase moving through a chromatographic column filled with a stationary phase (sorbent) serves as a mobile phase. Depending on the mechanism of substances separation distinguish the following options for HPLC: adsorption, distribution, ion exchange, exclusion, chiral. Depending on the type of mobile and stationary phase, normal phase and reverse phase chromatography are distinguished. ${ }^{3,25,26}$

The undoubted advantage of the HPLC method is efficiency and selectivity, high sensitivity and speed of analysis, the ability to study almost any objects without any restrictions on their physicochemical properties, for example, boiling points or molecular weight.

In the analysis of CHD, the HPLC method solves the problem of qualitative analysis (identification) of BAS complex or individual compounds and quantification (separation and purification stage) ${ }^{27,28} \mathrm{OA}$, as a rule, are determined under the conditions of reverse phase HPLC (RP HPLC). ${ }^{29-31}$ The separation of OA occurs in a chromatographic column filled with octadecyl silica gel. Concentrations are determined using a spectrophotometric detector at a wavelength of $210 \mathrm{~nm}$ using the external standard method. ${ }^{32,33}$ There are various conditions for analysis and equipment. For example, it is possible to use a Gilson HPLC system with the subsequent computer processing of the research results using the "Multichrome" program for "Windows" (column "Alltech OA-1000 Organic Acids" $6.5 \times 300 \mathrm{~mm}, 9 \mu \mathrm{m}$ ). The obtained chromatogram is presented at Figure 5. 


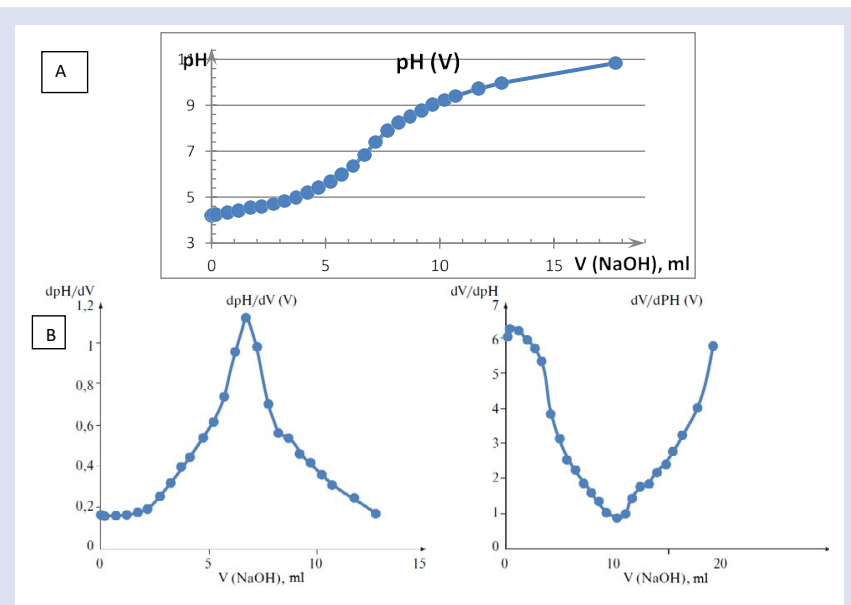

Figure 4: Titration curves of organic acids with sodium hydroxide solution $(0.1 \mathrm{M})$ in the rose hips extract: A - integral titration curve; B differential titration curves.

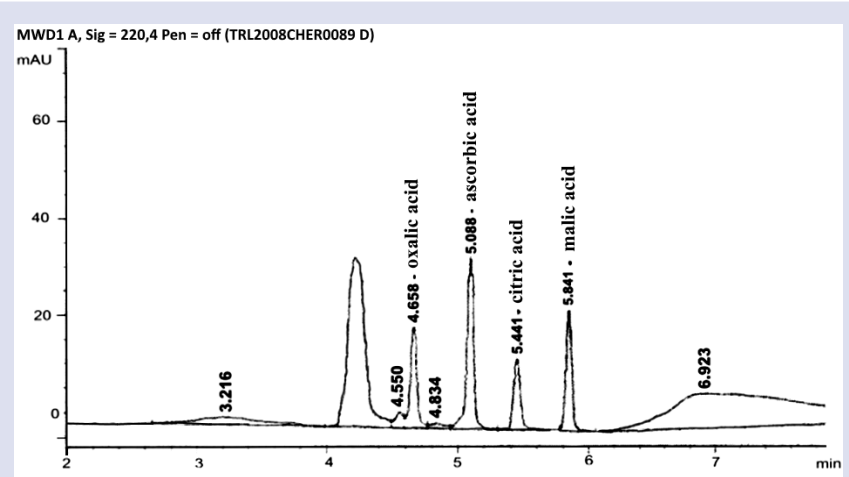

Figure 5: HPLC-UV chromatogram of OA in bilberry fruits extract.

\section{CONCLUSION}

Galvanostatic coulometry and potentiometry methods, as well as reverse-phase high-performance liquid chromatography, can be successfully used in the quality control of crude herbal drugs and medicinal herbal preparations, specifically fruits of Rosaceae family plants. Development and validation of analytical methods for monitoring the content of this BAS group is an important research area in the pharmacopoeial standardization of crude herbal drugs. ${ }^{34}$

RP HPLC with UV-detection is the most promising method for pharmacopoeial analysis in Russian Federation because it provides an opportunity to carry out qualitative and quantitative analysis simultaneously; at the same time, it makes possible determination of the identity and high-quality indicators. HPLC-DAD "fingerprints" of OA profile can serve as an important proof of crude herbal drug identity. ${ }^{35,36}$

\section{ACKNOWLEDGMENT}

Supported by the "Russian Academic Excellence Project 5-100". («Sechenov First Moscow State Medical University Program 5-100», «RUDN University Program 5-100»).

\section{CONFLICTS OF INTEREST}

None.

\section{REFERENCES}

1. State Register of Medicines. The Russian Federation Ministry of Health [Officia site]. URL:http://grls.rosminzdrav.ru/grls.aspx [Last accessed on 2019 June 07].

2. USSR State Pharmacopoeia, XI ed., Vol. 2. Moscow:Medicine 1989;400.

3. State Pharmacopoeia of the Russian Federation. Ed. $12^{\text {th }}$. Moscow:Scientific Center for Expertise of Medical Products 2008;704.

4. Edwards JE, Brown PN, Talent N, Dickinson TA, Shipley PR. A review of the chemistry of the genus Crataegus. Phytochemistry. 2012;79:5-26.

5. Caliskan O. Mediterranean Hawthorn fruit (Crataegus) species and potentia usage. The Mediterranean Diet. Academic Press, 2015. 621-628.

6. Liepina I, Nikolajeva V, Jākobsone I. Antimicrobial activity of extracts from fruits of Aronia melanocarpa and Sorbus aucuparia. Environ Exp Biol. 2013;11(4):195-

7. Mikulic-Petkovsek M, Schmitzer V, Slatnar A, Stampar F, Veberic R. Composition of sugars, organic acids, and total phenolics in 25 wild or cultivated berry species. J Food Sci. 2012;77(10):1064-70.

8. Krivoruchko EV, Andrushchenko OA, Kononenko AV. Carboxylic Acids from Sorbus aucuparia and S. aria. Chem Nat Compd. 2013;49(4):742-3.

9. Çekiç Ç, Özgen M. Comparison of antioxidant capacity and phytochemical properties of wild and cultivated red raspberries (Rubus idaeus L.). J Food Compos Anal. 2010;23(6):540-4

10. Haffner K, Rosenfeld HJ, Skrede G, Wang L. Quality of red raspberry Rubus idaeus L. cultivars after storage in controlled and normal atmospheres. Postharvest Biol Tec. 2002;24(3):279-89.

11. Golubtsova J. Assessing quality of fruit raw material for developing a method of its identification in food products. J Pharm Sci Res. 2017;9(5):504.

12. Sagdic O, Aksoy A, Ozkan G. Evaluation of the antibacterial and antioxidant potentials of cranberry (gilaburu, Viburnum opulus L.) fruit extract. Acta Alimentaria. 2006;35(4):487-92

13. Cam M, Hisil Y, Kuscu A. Organic acid, phenolic content, and antioxidant capacity of fruit flesh and seed of Viburnum opulus. Chem Nat Compd. 2007;43(4):460-461.

14. Krasnov EA, Blinnikova AA. Physico-chemical methods in the analysis medicines. Tomsk:Siberian State Medical University 2011;163.

15. Marakhova Al, Sergunova EV, Avrach AS. Methods for the quantification of organic acids in raw medicinal plant materials and aqueous extracts. Pharmacy. 2013;4:8-11.

16. Sergunova EV. Ascorbic acid stability and a procedure for raw plant materia preservation. Pharmacy. 2014;4:13-16

17. Abdullina SG. Galvanostatic coulometry in pharmaceutical analysis. Pharmacy 2012;5:54-56.

18. Abdullina AG, Lira OA, Agapova NM, Petrova IK, Ziyatdinova GK, Budnikov GK, et al. Coulometric analysis of medicines and raw medicinal plant materials. Pharmacy. 2014;3:5-6.

19. Abdullina SG, Agapova NM, Lira OA, Khaziev RS, Kodryanu NP. Coulometric determination of the free organic acid content in wild-rose fruit. Pharmaceutical Chemistry Journal. 2011;45(5):282-4.

20. Abdullina SG, Agapova NM, Khaziyev RSh, Sidullina SA. Determination of organic acids in mountain ash (Sorbus aucuparia) fruits. Pharmacy. 2011;2:17-9.

21. Belyaev AP. Physical and colloidal chemistry. Moscow: "GEOTAR-Media" 2008;704.

22. Marakhova Al. Potentiometry in the analysis of raw medicinal plant material and its based drugs. Pharmacy. 2013;3:53-5.

23. Marakhova Al, Sorokina AA, Sergunova EV, Fedorovskii NN. Advantages of potentiometric analysis of medicinal herbal raw materials and related drugs. Russian Chemical Bulletin. 2014;63(5):1251-4.

24. Marakhova Al, Supakova OA, Fedorovsky NN, Sergunova EV, Sorokina AA Development of a procedure for potentiometric determination of the sum of organic acids in briar (Rosa) fruits. Pharmacy. 2013;1:24-7.

25. Corradini C Cavazza A Bignardi C. High-performance anion-exchange chromatography coupled with pulsed electrochemical detection as a powerful tool to evaluate carbohydrates of food interest: principles and applications. Int J Carbohydr Chem. 2012;2012:487-500. 
26. Ikegami T, Horie K, Saad N, Hosoya K, Fiehn O, Tanaka N. Highly efficient analysis of underivatized carbohydrates using monolithic-silica-based capillary hydrophilic interaction (HILIC) HPLC. Anal Bioanal Chem. 2008:391(7):2533.

27. Jaafar N, Hamad M, Abbas I, Jaafar I. Qualitative phytochemical comparison between flavonoids and phenolic acids contents of leaves and fruits of Melia azedarach (family:Meliaceae) cultivated in Iraq by HPLC and HPTLC. Int J Pharm Pharm Sci. 2016;8(10):242-50.

28. Seal T. HPLC determination of phenolic acids, flavonoids and ascorbic acid in four different solvent extracts of Zanthoxylum acanthopodium, a wild edible plant of Meghalaya state of India. Int J Pharm Pharm Sci. 2016;8(3):103-9.

29. Romero Rodriguez MA, Vazquez Oderiz ML, Lopez Hernandez J, Lozano JS Determination of vitamin $C$ and organic acids in various fruits by HPLC. J Chromatogr Sci. 1992;30(11):433-7.

30. Scherer R, Rybka ACP, Ballus CA, Meinhart AD, Teixeira Filho J, Godoy HT. Validation of a HPLC method for simultaneous determination of main organic acids in fruits and juices. Food Chem. 2012;135(1):150-4.
31. Nour V, Trandafir I, lonica ME. HPLC organic acid analysis in different citrus juices under reversed phase conditions. Not Bot Horti Agrobo. 2010;38(1):44-8.

32. Guidance on methods for quality control and biologically safety active food additives P 4.1.1672-2003. M .:Russian Ministry of Health 2004;183.

33. European Pharmacopoeia. Seventh Edition. Vol. 1, Vol. 2, Supplement 7.1-7.8 EDQM, 2011-2012.

34. Sahoo N, Manchikanti P, Dey S. Herbal drugs:standards and regulation. Fitoterapia. 2010;81(6):462-71.

35. Springfield EP, Eagles PKF, Scott G. Quality assessment of South African herbal medicines by means of HPLC fingerprinting. J Ethnopharmacol. 2005:101(13):75-83

36. Nikam PH, Kareparamban J, Jadhav A, Kadam V. Future trends in standardization of herbal drugs. J Appl Pharm Sci. 2012;2(06):38-44.

\section{GRAPHICAL ABSTRACT}

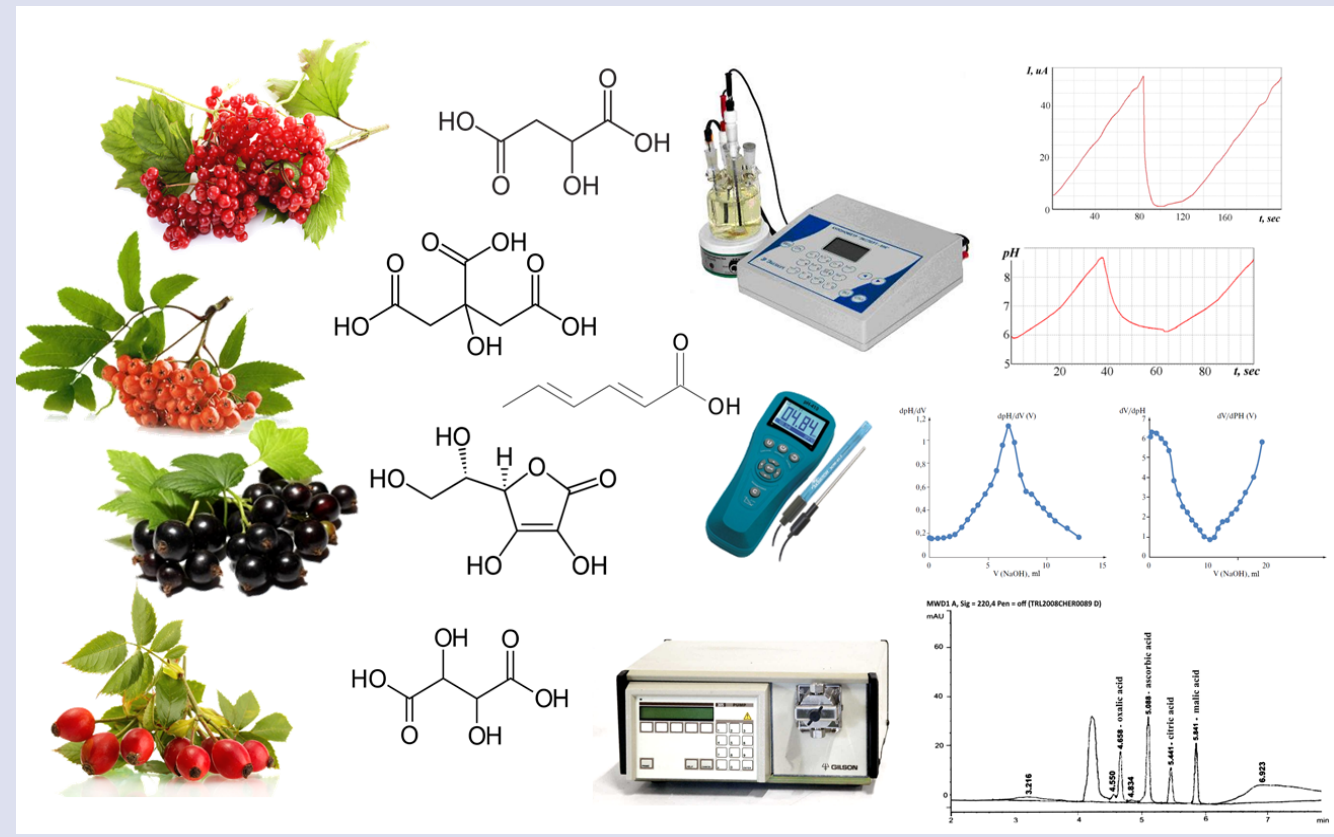

\section{ABOUT AUTHORS}

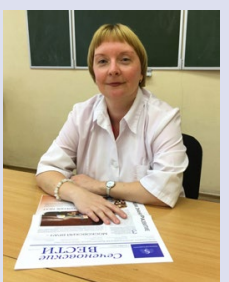

Sergunova Ekaterina Vyacheslavovna: is doctor of Pharmaceutical Sciences, Associate Professor, Professor of Department of Pharmaceutical Natural Sciences, Institute of Pharmacy, Sechenov University. Research Interests: are pharmacognosy, influence of conservation methods on the composition and content of biologically active substances in medicinal plant materials.

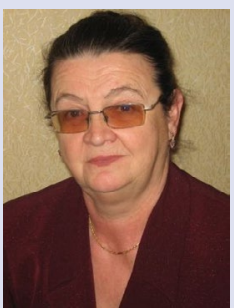

Sorokina Alla Anatolyevna: is doctor of Pharmaceutical Sciences, Professor, Professor of Department of Pharmaceutical Natural Sciences, Institute of Pharmacy, Sechenov University. Research Interests: are pharmacognosy, medicinal plants metabolome research, standardization of medicinal plant materials and mixture herbal products, standardization of water extracts (infusions, decoctions), total herbal preparations (tinctures, extracts, etc.), development of regulatory documentation for medicinal plant materials and mixture herbal products. 


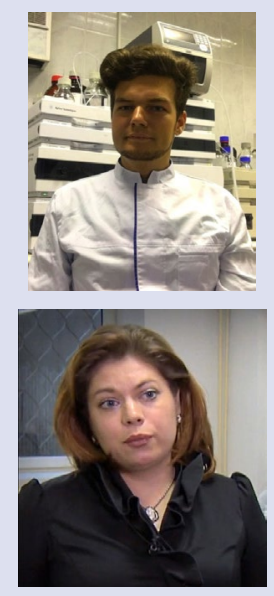

Bokov Dmitry Olegovich: is candidate of Pharmaceutical Sciences (Ph.D.), Associate Professor, Department of Pharmaceutical Natural Sciences, Department of Analytical, Physical and Colloid Chemistry, Institute of Pharmacy, Sechenov University; Laboratory of Food Chemistry, Federal Research Center for Nutrition, Biotechnology and Food Safety. Research Interests: are pharmacognosy, analytical chemistry, investigation of the composition and content of biologically active compounds in crude herbal drugs using modern instrumental methods of analysis (HPLC with RID, UV, MS-MS detection, GC-MS).

Marakhova Anna Igorevna: is doctor of Pharmaceutical Sciences, Professor, head of Institute of Biochemical Technology and Nanotechnology, Peoples' friendship university of Russia (RUDN University). Research Interests: are pharmacognosy, unification of physico-chemical methods of analysis of medicinal plant materials and herbal preparations.

Cite this article: Sergunova EV, Sorokina AA, Bokov DO, Marakhova Al. Qualitative and Quantitative Determination of Organic Acids in Crude Herbal Drugs and Medicinal Herbal Preparations for Quality Control in Russian Federation by Modern Physicochemical Methods. Pharmacog J. 2019;11(5):1132-7. 